a community of origin being thereby probably indicated. M. P. Carrasco now points out (Comptes rendus, vol. clxi., p. 63I) that there is an additional member of this series, the next earlier term being the red line at $\lambda 6374 \cdot 2$. This line, unknown when Prof. Nicholson was pursuing his investigations, was the most important feature of the coronal spectrum as photographed at the late eclipse (August 2I, 1914), and M. Carrasco was one of the fortunate observers who obtained a record of the line.

Areas of Absorption Markings on SectrohelioGRAMS. - The results of the limb prominence observations made at Kodaikanal Observatory during the first half of the current year are given in Bulletin No. 47 . The mean daily area is the largest since 1908, and shows an increase of 59 per cent. over that for the preceding six months. Prominences seen projected on the disc as absorption markings on spectroheliograms taken in the light of the $\mathrm{H}_{\alpha}$ reversal are being specially recorded with the grating spectroheliograph for measurement. Mean daily areas in millionths of the sun's visible hemisphere and mean daily numbers for the five half-years $19^{12-13}$, and January-June, 1915, are published in the above bulletin. For the second half of I9I3 the areas were sixty, whilst for the first half of the present year they were 1375.6 . The distribution in latitude of these markings shows the prominence maximum between $50^{\circ}$ and $60^{\circ}$, together with a pronounced maximum about $30^{\circ}$, due to prominence in spot latitudes, the equator being avoided, as in the case of sun-spots.

\section{THE CORROSION OF METALS.}

$\mathrm{O}^{\mathrm{N}}$ December 8, under the presidency of Sir Robert Hadfield, the Faraday Society held a discussion on the corrosion of metals. Of the seven papers contributed, only two dealt with the more general aspects of this very important question. Three were concerned with the corrosion of iron, and some of the numerous steels which find application in modern industrial life; the remaining two had reference principally to marine condenser tube alloy, $70: 30$ brass. As it turned out, there was almost no discussion on the fundamental characteristics of corrosion phenomena. During the first hour instances of corrosion among iron alloys came under review, the remainder of the evening being devoted to a consideration of the corrosion of copper-zinc alloys.

As Dr. Rideal pointed out in his printed contribution to the more fundamental aspects of the question, "the phenomena observed in the corrosion of metals are to be found scattered among the earliest records of mankind, and in consequence of the universality of the subject we have received a heritage consisting of a jumble of facts and theories." The first report by Dr. Bengough to the Corrosion Committee of the Institute of Metals consists mainly of a critical examination of the views held with regard to the cause, or causes, of the corrosion of marine condenser tube alloy, the general conclusion being that the evidence is so conflicting that no particular view can be regarded as at all firmly established. The committee, therefore, in planning the experimental investigation decided that there was nothing for it but to begin at the very beginning and take nothing for granted.

Dr. Rideal's definition of corrosion is as follows :"Corrosion may be said to result from an irreversible chemical change proceeding with a small velocity and taking place on the common surfaces between two or more phases, the products of which change are continually removed from the sphere of action." Moreover, it takes place generally on the surfaces of phases which are electrically conducting, a fact which lies at the base of the now generally accepted electrolytic theory of corrosion. This theory requires the presence of minute cells operating on the surface of the corroded metal or alloy. As yet, however, there is no information as to the number of such cells or the rate at which they work.

Dr. Desch's contribution dealt with the influence of physical and mechanical factors in corrosion, an aspect of the subject the importance of which is by no means always adequately realised. Although the process of corrosion is probably in all cases initially one of chemical solution, the physical heterogeneity of the metal or alloy has a considerable influence on its nature and velocity. More especially has this to be considered when it is remembered that many of the commonly used industrial alloys are in a "strained" condition, and contain, as Dr. Beilby has shown, films of amorphous material on the surfaces of slip of the crystals. Such films have been demonstrated to be more electropositive than the crystalline material, a fact which determines the course of corrosion of cold-worked metals in particular. The increased corrodibility of such alloys is no doubt also partly to be ascribed to the energy produced by work being stored up in these films.

The Cumberland process for preventing the corrosion of metals immersed in liquids, of which a demonstration was given at the close of the discussion, is based upon a recognition of the galvanic nature of this phenomenon. It consists in introducing a higher counter-electromotive force to that causing the corrosive action. A continuous current working at ro volts is supplied to the anode, consisting of pieces of iron suspended in the liquid and insulated from the vessel being protected. It is claimed that this system has been in use in all types of steamships and in many large power plants, and that it is applicable to any metal in contact with water or any other corrosive liquid.

H. C. H. Carpenter.

\section{VISCOSITY OF OILS.}

THE Institution of Petroleum Technologists is one $I$ of the most recent of our technological associations. Founded in $19 \mathrm{I} 3$, to advance the study of mineral oils from the various points of view of the chemist, the geologist, the engineer, the prospector, and the financier, it has shown from the first a healthy vitality and the promise of a vigorous future. At a general meeting held on November 16 , at the Royal Society of Arts, the institution had the pleasure of listening to an illuminating address by Dr. Glazebrook on the viscosity of oils in relation to the rate of flow through pipes. The tests described had been undertaken at the request of the Admiralty, and permission had been given for their publication. The results of the investigation showed that the ordinary law of viscous flow, $\mathrm{P} / \mathrm{V}=2 \eta / 9 g d^{2}$, holds good in the particular case postulated so long as the critical velocity which is given in the expression $\rho \mathrm{Vd} / \eta=2500$ is not exceeded.

Many experimental difficulties were met with in the actual measurements, which were carried out in the engineering department of the National Physical Laboratory by Mr. Pannell. The small variations in pressure were measured by means of a sensitive mercury tilting gauge, and the quantity of oil passed per minute through the pipes was measured on an Avery weighing machine. Thermal changes were eliminated by jacketing and careful electrical heating.

In general excellent agreement was found between the calculated and observed values of $P / V$ through a wide temperature range.

Part ii. of the research was occupied with the determination of the physical contents of the various oils which were used. The densities call for little comNO. 2407 , vOL. 96] 